\title{
Could an osteoinductor result in degeneration of a neurofibroma in NF1?
}

\author{
Steib Jean-Paul $\cdot$ Bouchaïb Julia $\cdot$ Walter Axel · \\ Schuller Sébastien · Charles Philippe
}

Received: 5 April 2010/Accepted: 17 April 2010/Published online: 7 May 2010

(C) Springer-Verlag 2010

\begin{abstract}
We report a case of fatal evolution of neurofibromatosis in a young boy. A laminectomy was performed when he was 9 years old. A secondary hyperkyphosis led to many surgeries resulting in recurrent malunions. When he was 23 years old, a breakage of his rods was treated by a new instrumentation and a T12-L1 interbody cage fitted with rh-BMP. Five months later, he developed a huge posterior tumour on his back. The biopsy diagnosed a neurofibrosarcoma. The growth of the tumour was extremely rapid. He died after several months from a septic shock. NF1 is characterised by neurofibromas that have a possibility of malign degeneration and conversion to a sarcoma. However, the chronology, rapidity of evolution and the exceptional volume of the tumour made us wonder whether the BMP had a part of responsibility as osteoinductor in the malignant degeneration, in this particular case, of neurofibromatosis. It seemed important to point out this case to the medical community.
\end{abstract}

Keywords NF1 - Recklinghausen $\cdot$ Malunion ·

Neurofibrosarcoma · Osteoinductor - Rh-BMP .

Laminectomy $\cdot$ Spine

\section{Introduction}

Neurofibromatosis type 1 was diagnosed in a 5-year-old boy. He had melanic marks (coffee with milk colour) on

S. Jean-Paul ( $₫)$ · B. Julia · W. Axel · S. Sébastien ·

C. Philippe

Service de Chirurgie du Rachis,

Hôpitaux Universitaires de Strasbourg,

Pavillon Chirurgical B, B.P. 426, 67091 Strasbourg

Cedex, France

e-mail: jean-paul.steib@chru-strasbourg.fr his legs and abdomen. Biopsy of skin nodes indicated plexiform neurofibroma. His mother, also affected by NF1, died from a neurofibrosarcoma of the radial nerve. His three brothers presented with coffee with milk-coloured marks, but without any other expression of the disease apart from a slight, nonevolutive scoliosis. When he was 6 years old, an extensive laminectomy (T9-T11) was performed for a spinal cord compression by a neurofibroma (Fig. 1). As often is the case in children, he developed a severe hyperkyphosis 3 years later consequent to this laminectomy [1-5]. At this stage, at age 9 years, the patient came to our care. Surgery was performed first by an anterior release and tibial bone grafting (pallissade) from $\mathrm{T} 8$ to $\mathrm{T} 12$, followed by a posterior instrumentation with fusion from T5 to L1 (baby CD). The first follow-up was uneventful.

The growth was marked by the development of a neurofibroma, especially in front of the lumbar spine. Surgical removal by a retroperitoneal curettage became necessary. Histology of the tissue confirmed the diagnosis of neurofibroma without malignancy. This surgery was complicated by a lymphocele with spontaneous drying. A recurrence of the neurofibroma was noticed on the abdomen, yet on the trajectory of different nerves. The orthopaedic evolution was marked by different nonunions necessitating new surgeries with new instrumentations, extension of the fusion area and adjunction of interbody bone grafting. The first nonunion was diagnosed at the occasion of a progressive paraplegia caused by the hyperkyphosis. He recovered with traction and a new posterior instrumentation with fusion was performed. During these several surgeries, many different fibromas were resected, each time without any sign of malignity.

At 23 years old, he developed again nonunion with posterior dismantling of the instrumentation (Fig. 2). This 
Fig. 1 Paraspinal neurofibroma at 9 years old: thoracic hyperkyphosis after wide laminectomy
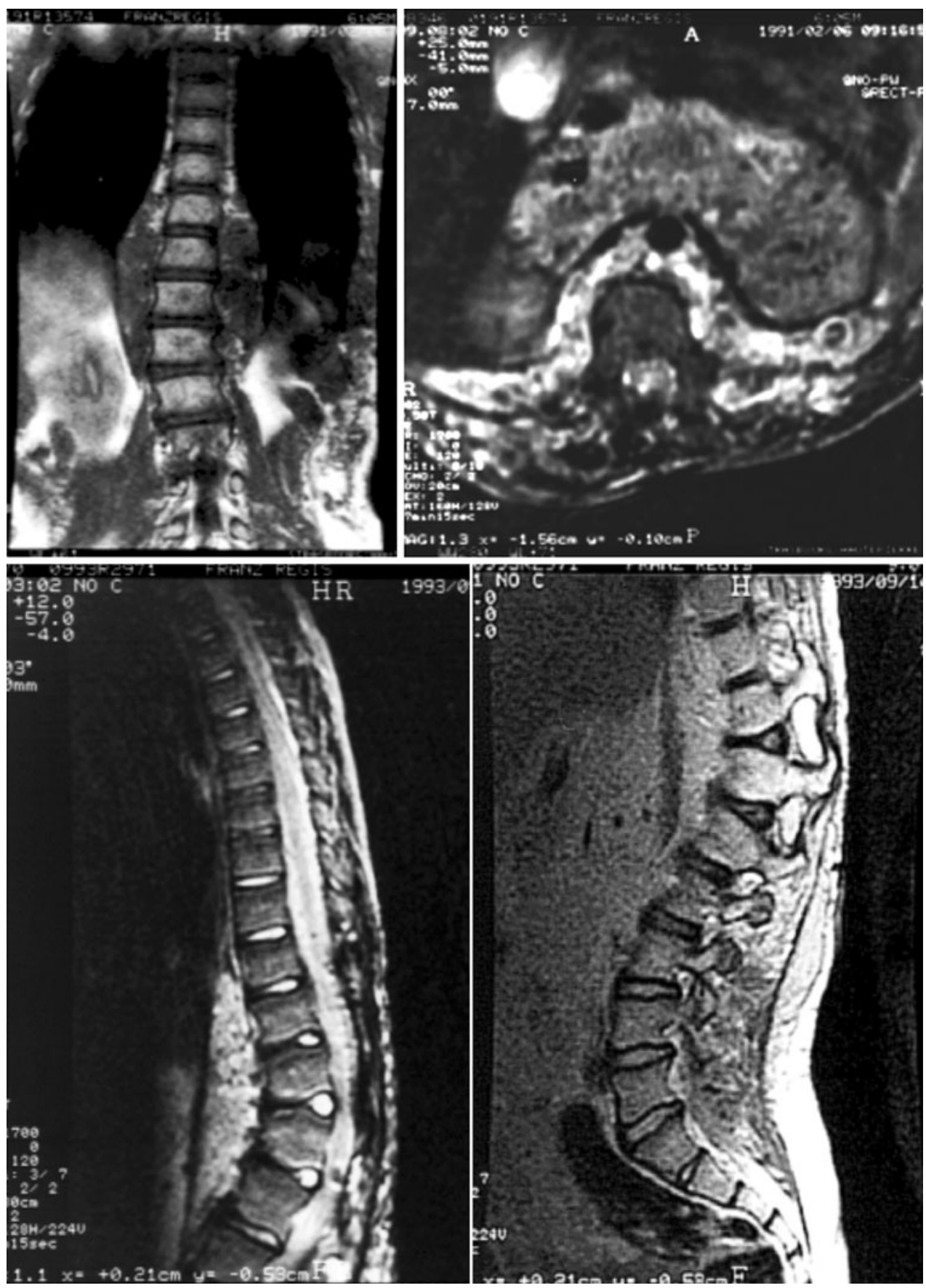

nonunion resembled a Charcot spine [6] with a real interbody neoarticulation. New rods were inserted (Fig. 3) and an interbody cage fitted with RhBMP2 (Inductos*, Infused*, Medtronic Sofamor Danek) was inserted at T12-L1. Five months later, he consulted for a lump on the back, which he attributed to a rod breakage. In fact, the deformity was a massive tumour on the anterior part of the spine, including the big vessels and the pancreas, and protruding from the skin on the left side (Fig. 4a). A biopsy showed a diagnosis of neurofibrosarcoma. At that time, surgery was not possible anymore [Conti, Starck]. Palliative treatment was started as the patient weakened progressively and the tumour continued to grow (Fig. 4b), becoming massive with skin ulceration and necrosis. He died 6 months after the diagnosis of neurofibrosarcoma from a septic shock and severe anaemia (Fig. 5).

\section{Discussion}

NF1 is characterised by neurofibromas with possible degeneration and conversion to a sarcoma [7-12]. His 
Fig. 2 At 23 years old: nonunion with posterior dismounting
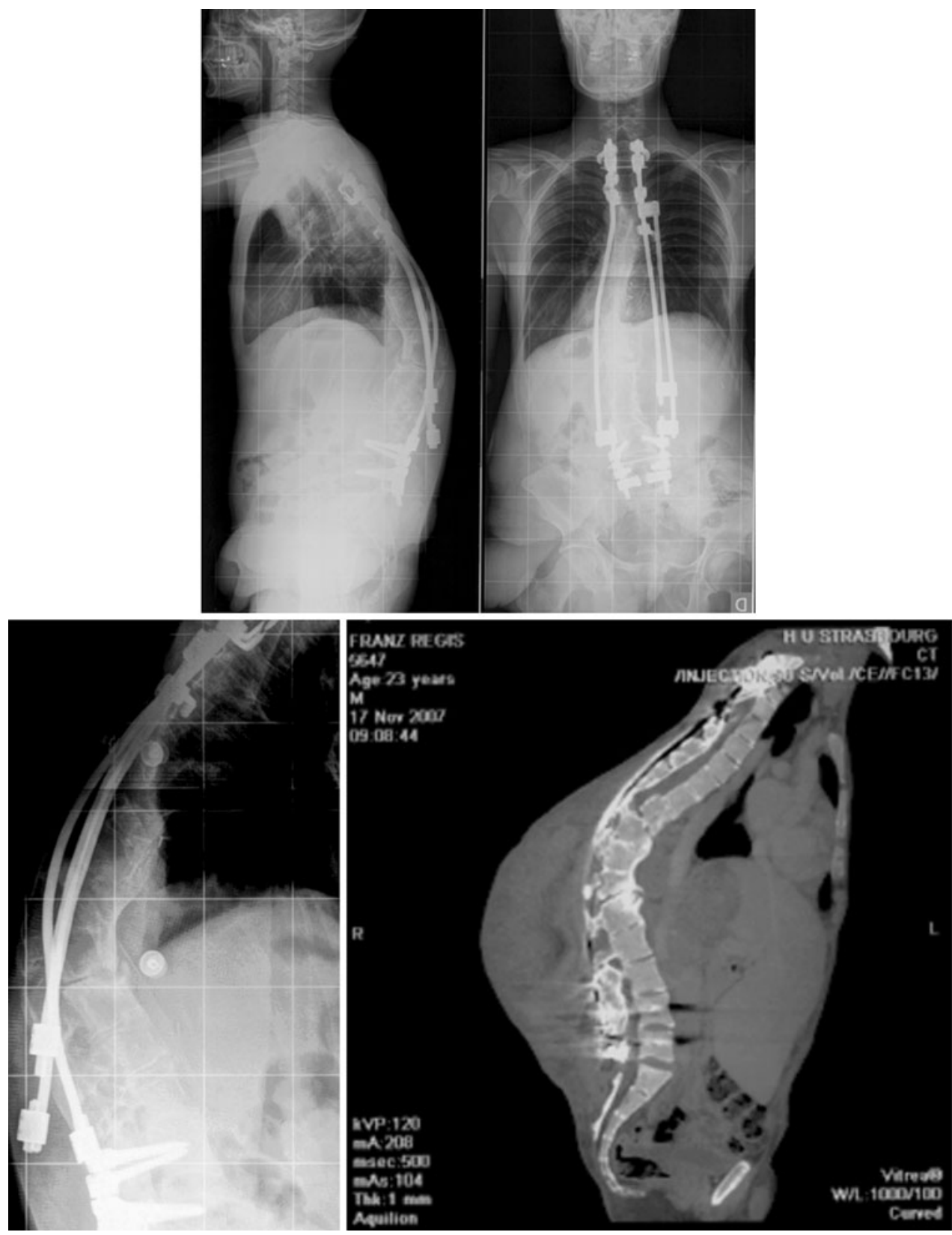

mother had the same disease and died before her 30th birthday from a malign degeneration of a neurofibroma of the forearm.

The reason for malignity can be genetically explained $[12,13]$ Indeed, NF1 is caused due to balanced translocation of the short arm of chromosomes 12 and 17 (exchange of chromosomal material). For NF1, the break of DNA in the mutated gene is near the oncological locus (ERB-A1 on chromosome 17 and SIS on chromosome 22). The expression of this oncological locus could be disturbed by the mutation (end of inhibition for their transcription). Because of its location near oncogenes, the mutation causing NF1 would expose to the risk of malignancy.
We find many different clinical presentations of NF1, mostly with skin marks (coffee with milk-coloured marks) and neurofibromas. Different bone diseases have been described (scoliosis, kyphosis) [14-21] with many nonunions complicating their treatment. A high incidence of congenital tibial malunion [24] was described in a child who was a carrier of NF1. Late consolidation or real nonunion in traumatic fracture is common in these patients, probably due to an insufficient quality of osteogenesis [25] compared to normal subjects. The difficulty of taking care of these patients is well known, in particular regarding the surgical treatment of scoliosis $[14,16,17,21]$. 


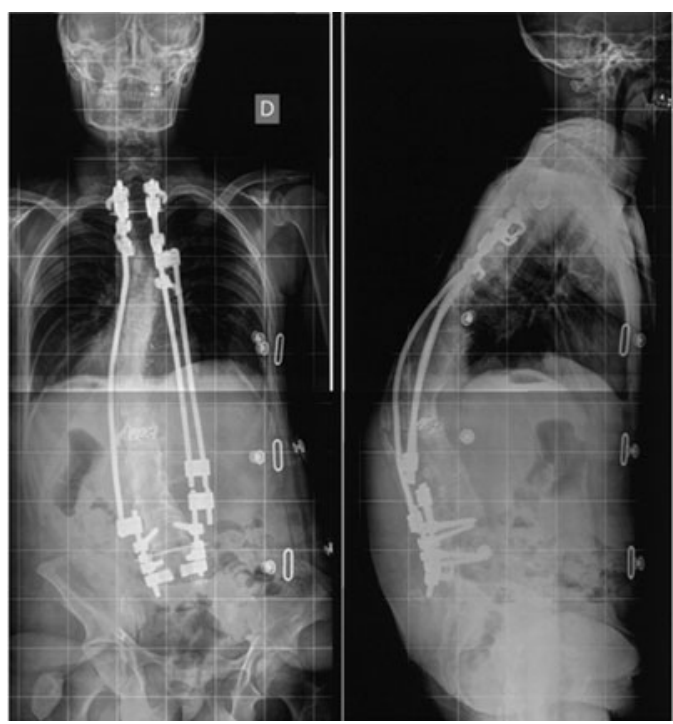

Fig. 3 Change of the rods and interbody cage with rhBMP-2
Mechanical factors and local particularities enhanced the predisposition of our patient to developing a nonunion:

- The primitive left lumbar tumour (first surgery) with benign histology presented signs of local aggressivity, particularly towards the spine. The resection of the tumour was not complete because of its topography, extension and functional implications of a more aggressive treatment option.

- Repeated surgeries (wide laminectomies, anterior interbody releases) had destabilised the spine more or less fixed by instrumentation. The last few surgeries left a large area only covered by rods, with the anchorage existing only at the upper and lower parts of the construct. Growth also played a part in the bad evolution: the spine of this boy was composed of rigid sections (epiphysiodeses, fusion masses) alternating with transitional sections, with a lot of constraints on distraction, compression and flexion.
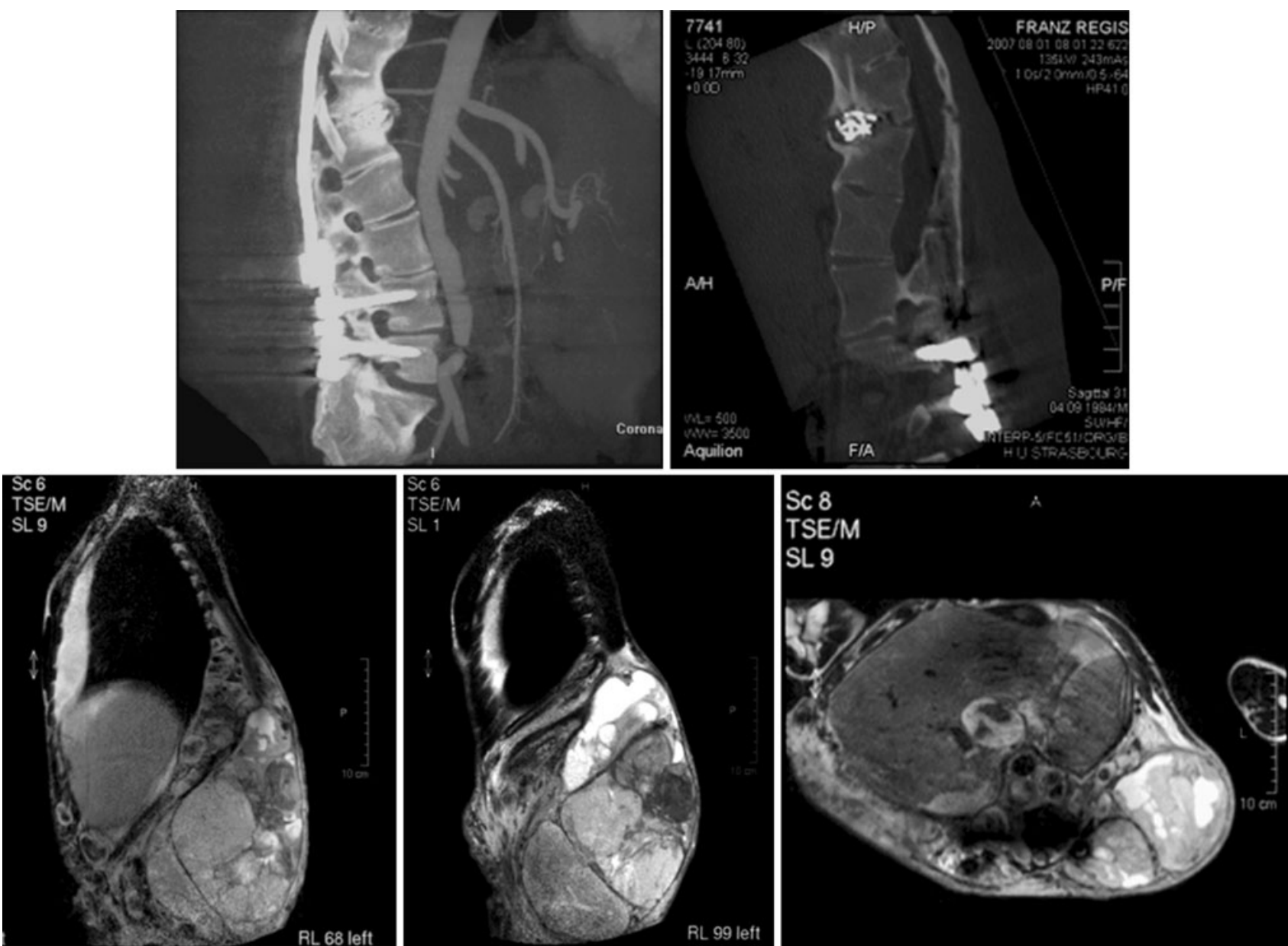

Fig. 4 Four months later: osteosarcoma 
Fig. 5 Clinical aspect of the tumour before and after necrosis
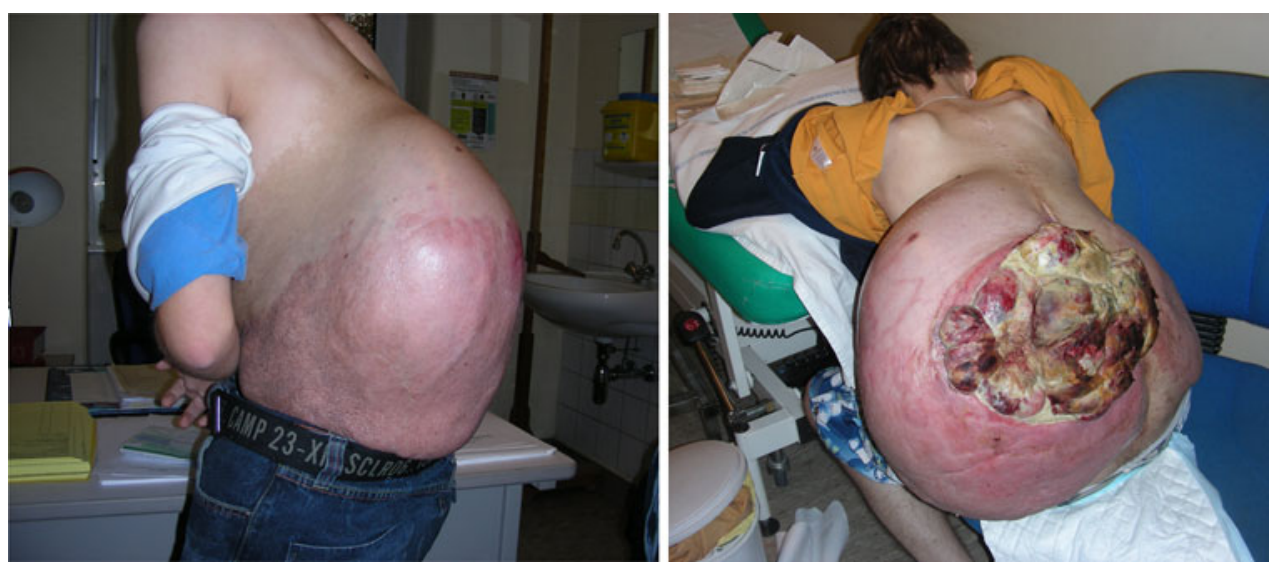

The tendency for nonunion in NF1, the recurrence of rod breakage with evident malunion and the absence of autologous bone ( 2 iliac crests, 2 tibias already taken) caused us to use an osteoinductor to facilitate interbody fusion in the cage.

Consolidation could not be achieved as, in the weeks following the use of BMP, we were confronted with a devastating evolution of the disease. The volume of the tumour grew enormously with a local aggressivity, corresponding to degeneration of the neurofibroma towards a sarcoma.

The chronology, as well as the rapidity of the evolution and the exceptional volume of the tumour, made us wonder whether the BMP had a part of responsibility as osteoinductor in the malignant degeneration of this particular neurofibromatosis case. Could the use of osteoinductor interfere with the natural evolution of the NF1? Could BMP accelerate the degeneration of the neurofibroma into a sarcoma?

BMPs (bone morphogenetic proteins) belong to the family of TGF $\beta$ and play a physiological role in the process of enchondral ossification [22]. Nevertheless, their participation in oncological phenomena has been documented [22, 23]. Indeed, synthesis of BMP was found in cells of tumours (osteosarcoma, chondrosarcoma, osteoblastoma, osteoid osteoma) [22] and the BMP rate was proposed to be used as a prognostic factor [22]. It was demonstrated in vitro that chondrosarcomatous cells exposed to BMP-2 could acquire the properties of migration particular to malignant cells [23].

These phenomena could involve the activation of metalloproteases (MMP-13 especially) through BMP-2. These metalloproteases are responsible for the degradation of the cartilage matrix (collagen type 2) allowing the migration of chondrosarcoma cells.

However, to our knowledge, no study has reported on the possible role of BMP in the process of malignisation of nonosseous or cartilaginous tumour. The participation of $\mathrm{BMP}$ in the process of cell migration of tumours already degenerated has been demonstrated [23]. To date, no study has reported the transformation of benign tumour cells to malignant tumour cells in the presence of BMP.

For our patient, the chronology of events suggested the involvement of BMP in the transformation of neurofibroma (local aggressive potential, but without malignity) to neurosarcoma.

\section{Conclusion}

This clinical case raises questions about the use of osteoinductors in patients who are carriers of a benign tumoural disease. Although we cannot prove that BMP was the direct cause of the unfortunate evolution in our patient, we felt that is was important to report the case. If such inductors can play a role in the malignant transformation of bone cells, they perhaps could be able to have an effect on other lines of cells: at which step and to what degree is an open question. Perhaps they have transformed a benign pathology into a malign one, or perhaps they have accelerated an already bad evolution present before their use?

We cannot conclude from a single case. Nevertheless, this case has led us to advise caution with the use of osteoinductors. BMP should only be used in indications without any ambiguity. At a time where BMP is used more and more, it seemed appropriate to report this unfortunate case.

Conflict of interest statement None of the authors has any potential conflict of interest.

\section{References}

1. Albert TJ, Vacarro A (1998) Postlaminectomy kyphosis. Spine 23(24):2738-2745

2. Dubousset J (1989) Traitement des fractures du rachis chez l'enfant, in Bollini, Chirurgie et orthopédie du rachis (enfant et adolescent), Sauramps Medical 
3. Dubousset J, Guillaumat M, Mechin JF (1973) Retentissement rachidien des laminectomies chez l'enfant. In: Rougerie J (ed) Les compressions médullaires non traumatiques chez l'enfant. Masson, Paris

4. Ghanem I, Dubousset J. 1995. Place de l'instrumentation dans les tumeurs vertébrales de l'enfant, in Instrumentation rachidienne, JG Pous, J Duparc Ed., Cahiers d'enseignement SOFCOT

5. Ghanem I, Zeller R, Dubousset J (1996) Tumeurs extrasquelettiques du rachis chez l'enfant et l'adolescent: problèmes rachidiens. Rev Chir Orthop 82:313-320

6. Schwartz HJ (1990) Traumatic Charcot spine. J Spinal Disord 3(3):265-275

7. Ferrari A, Bisogno G, Macaluso A, Casanova M, D'Angelo P, Pierani P, Zanetti I, Alaggio R, Cecchetto G, Carli M (2007) Soft tissue sarcomas in children and adolescent with neurofibromatosis type 1. Cancer 109(7):1406-1412

8. Neville H, Corpron C, Blakely ML, Andrassy R (2003) Pediatric neurofibrosarcoma. J Pediatr Surg 38(3):343-346

9. Kett-White R, Martin JL, Jones EW, O'Brien C (2000) Malignant spinal neurofibrosarcoma. Spine 25(6):152-155

10. Boulanger JM, Larbrisseau A (2005) Neurofibromatosis type 1 in a pediatric population : Ste Justine's experience. Can J Neurol Sci 32(2):225-231

11. Tekaya R, Hamdi W, Azzouz D, Bouaziz M, Jaafoma MH, Ladeb MF, Kchir MM (2008) Cervicobrachial neuralgia revealing neurosarcoma. Rev Neurol (Paris) 164(1):82-86

12. Riccardi VM (2007) The genetic predisposition to and histogenesis of neurofibromas and neurofibrosarcoma in neurofibromatosis type 1. Neurosurg Focus 22(6):E3 (Review)

13. Decker HJ, Cannizzaro LA, Mendez MJ, Leong SP, Bixenman H, Berger C, Sandberg AA (1990) Chromosomes 17 and 22 involved in marker formation in neurofibrosarcoma in von Recklinghausen disease. A cytogenetic and in situ hybridization study. Hum Genet 85:337-342

14. Yalcin N, Bar-on E, Yazici M (2008) Impingement of spinal cord by dislocated rib in dystrophic scoliosis secondary to neurofibromatosis type 1: radiological signs and management strategies. Spine 33(23):E881-E886
15. Crawford AH, Herrera Soto J (2007) Scoliosis associated with neurofibromatosis. Orthop Clin North Am 38(4):553-562

16. Singh K, Samartziz D, An HS (2005) Neurofibromatosis type 1 with severe dystrophic kypho-scoliosis and its operative management via a simultaneous anterior-posterior approach: a case report and review of the literature. Spine J 5(4):461-466

17. Tsirikos Al, Saifuddin A, Noordeen MH (2005) Spinal deformity in neurofibromatosis type 1: diagnosis and treatment. Eur Spine J 14(5):427-439

18. Sales de Gauzy J, Abid A, Knorr J (2004) Orthopaedic complications of neurofibromatosis. Arch Pedriatr 11(6):553-554

19. Soultanis KC, Payatakes AH, Chouliaras VT, Mandellos GC, Pyrovolou NE, Pliarchopoulou FM, Soucacos PN (2007) Rare causes of scoliosis and spine deformity, experience and particular features. Scoliosis 2:15

20. Winter RB, Lonstein JE, Anderson M (1988) Neurofibromatosis hyperkyphosis: a review of 33 patients with kyphosis of 80 degrees or greater. J Spinal Disord 1(1):39-49

21. Dresher BD, Asher MA (2002) Thoracic kyphoscoliosis resembling neurofibromatosis: a case report focusing on subfascial instrumentation. Spine J 2(2):151-155

22. Yoshikawa H, Nakase T, Myoui A, Ueda T (2004) Bone morphogenetic proteins in bone tumors. J Orthop Sci 9:334-340

23. Hou CH, Hsiao YC, Fong YC, Tang CH (2009) Bone morphogenetic protein-2 enhances the motility of chondrosarcoma cells via activation of matrix metalloproteinase-13. Bone 44:233-242

24. Cho TJ, Seo JB, Lee HR, Yoo WJ, Chung CY, Choi IH (2008) Biologic characteristics of fibrous hamartoma from congenital pseudarthrosis of the tibia associated with neurofibromatosis type 1. J Bone Joint Surg Am 90(12):2735-2744

25. Brunetti-Pierri N, Doty SB, Hicks J, Phan K, Mendoza Londono R, Blazo M, Tran A, Carter S, Lewis RA, Plon SE, Phillips WA, O'brian Smith E, Ellis KJ, Lee B (2008) Generalized metabolic bone disease in neurofibromatosis type 1. Mol Genet Metab 94(1):105-111 